\title{
Crecer entre dos mundos: el portugués como lengua de herencia en España
}

\author{
Growing up between two worlds: \\ Portuguese as a heritage language in Spain
}

\author{
Juliana Azevedo Gomes \\ Docente e investigador, Universidad Europea del Atlántico \\ juliana.azevedo@uneatlantico.es \\ Código Orcid: http://orcid.org/0000-0003-0192-5323
}

\begin{abstract}
Resumen
Lengua y cultura son elementos determinantes en la construcción de la identidad de los individuos. Cuando un niño crece en un país distinto al de sus padres, esta identidad será más compleja, puesto que la lengua y cultura familiar serán distintas a la lengua y cultura del país donde vive. Este estudio de caso único de corte cualitativo realizado con un grupo de once familiares brasileños buscó identificar las estrategias utilizadas para la transmisión del portugués como lengua de herencia a sus hijos que crecen en España. Los resultados demuestran que a pesar de reconocer su rol de principal transmisor, los familiares consideran fundamental el soporte de otras instituciones para minimizar la restricción de contextos de comunicación en esta lengua.
\end{abstract}

\section{Palabras clave}

Inmigración, lengua de herencia, hablante de herencia, POLH, PLH.

\begin{abstract}
Language and culture are part of the identity construction of individuals. When a child grows up in a different country of his parents, his identity will be more complex, since there's an alive language and culture in his familiar environment, nevertheless, different from the majority language and culture of the country he lives.

This paper addresses to recognize the strategies of 11 Brazilian relatives immigrated to Spain to transmit the Portuguese as a heritage language to their children who live in Spain. The results point to an awareness about their primordial role in the heritage language transmission. Moreover, they recognize the support of an institution in order to minimize the communication restriction contexts in this language.
\end{abstract}

\section{Keywords}

Immigration, heritage language, heritage speaker, POLH, PLH.

Forma sugerida de citar: Azevedo-Gomes, Juliana (2019). Crecer entre dos mundos: el portugués como lengua de herencia en España. Universitas, 30, pp. 151-171. 


\title{
Introducción
}

\begin{abstract}
¿Pero qué es la lengua? Para nosotros, ella no se confunde con lenguaje, es solamente una parte determinada, esencial de ella, sin duda. A la vez es un producto social de la facultad del lenguaje y un conjunto de convenciones necesarias, adoptadas por el cuerpo social para permitir el ejercicio de esta facultad en los individuos (Saussure, 2008, p. 17).
\end{abstract}

Hace más de un siglo que la antropología y la sociología presentan estudios acerca de la cultura y de su relación con el lenguaje. Wilhelm von Humboldt (1767-1835, en Trujillo Sáez, 2006), subraya que el lenguaje permite la comprensión del mundo. "[...] el lenguaje media entre nosotros y el mundo y que percibimos este último por medio de las categorías del primero" (p. 79). Hall (2003) afirma que el lenguaje es uno de los medios de representación de una cultura y es por su intermedio que es posible comunicar ideologías, valores y sentimientos dentro de un contexto. A partir de la visión posmoderna, es posible comprender la cultura como un espacio de construcción de significados, donde el sujeto es activo en establecer relaciones entre la lengua y cultura. Para Benedict (1997) "[...] la cultura es una lente a través de la cual el hombre ve el mundo" (p. 12). La lente en este caso es el componente subjetivo, fruto de las experiencias del sujeto con el contexto.

En el caso de la transmisión de una lengua mayoritaria, la cultura es transmitida de manera natural, resultado del tejido de relaciones sociales que un sujeto tratará de construir a lo largo de su desarrollo biológico y social. Para Hall (2003), las culturas nacionales están constituidas de símbolos y representaciones y son un discurso y un camino para la construcción de sentido. En el caso de la transmisión de una lengua y cultura dentro del país de origen, los signos y los códigos lingüísticos y culturales son transmitidos a la vez, puesto que "Los sentidos están en las historias contadas sobre la nación, memorias que conectan su presente con su pasado e imágenes que de ella son construidas" (Hall, 2003, p. 51).

No obstante, esta realidad es resignificada cuando una lengua y cultura son importantes en el contexto familiar, sin embargo, distintas a la lengua y cultura mayoritarias del país de residencia. Como afirman Thomas y Peterson (2015), cuando una cultura no es familiar, desarrollar una profunda comprensión de una nueva cultura sería como intentar aprender un nuevo idioma con el mismo acento que habla su primera lengua, es decir, un desa- 
fío. Este es el caso dos hijos de inmigrantes que crecen en un país distinto a los de sus familiares.

Aunque conozcan la lengua y la cultura de la familia, no necesariamente dominan este lenguaje, pues no han emigrado adultos, como sus padres, sino que nacieron o emigraron con una edad muy temprana a otro país. Como no tienen la oportunidad de vivenciar la cultura familiar en otros contextos sociales ni siempre se identifican con ella. Asimismo, mantienen un vínculo repleto de significados y relacionado al sentimiento de pertenencia con este origen familiar. Esta lengua y cultura, distintas del entorno donde residen estos sujetos, es transmitida especialmente en el ámbito familiar y entre otras definiciones, la denominaremos lengua y cultura de herencia.

Este estudio es parte de una investigación doctoral y busca conocer la percepción de los familiares brasileños emigrados a España sobre su rol de transmisión de la lengua de herencia, las estrategias que utilizan y qué tipo de actitudes lingüísticas perciben de sus hijos, nacidos en España.

\section{Lengua de herencia}

La lengua de herencia, también conocida como lengua patrimonial o lengua ancestral (He, 2010; Van Deusen-Scholl, 2003), lengua colonial (Carreira, 2004; Fishman y Peyton, 2001), o incluso lengua minoritaria (Valdés, 2005), es el idioma de origen de las familias que, por alguna razón, migran a otro país donde la lengua es distinta a la suya. El término herencia está relacionado a su transmisión a los descendientes de los inmigrantes que hablan esta lengua. La lengua de herencia es un idioma de comunicación relacionado con un contexto sociocultural familiar, que ayuda a estructurar el pensamiento, los discursos y sus significados.

La cultura de herencia, así como la lengua, si no es transmitida por la familia, difícilmente será aprendida, puesto que en la mayoría de los casos, los descendientes de inmigrantes nacieron o llegaron en edad muy temprana al país de residencia y por lo tanto, vivencian diariamente una cultura distinta a la de herencia. Estos descendientes son conocidos como heritage speakers (hablantes de herencia). Esta terminología se presentó inicialmente en Canadá, país con elevado número de inmigrantes. Tras unos años, fue adoptada también por Estados Unidos y demás países (Cummins 2005), para identificar a los niños que aprendieron un idioma desde el nacimiento, pero tie- 
nen otra lengua dominante relacionada con el contexto donde viven. Según Cummins (2005), "[...] además de hijos de inmigrantes, los hablantes de herencia son los refugiados y los grupos indígenas [...]" (p. 586) que tienen de adaptarse en un nuevo contexto, conviviendo con otra lengua y cultura.

Van Deusen Scholl (2003) defiende que no necesariamente los hablantes de herencia hablan la lengua familiar, no obstante, poseen un fuerte vínculo afectivo intergeneracional con su origen. Montrul (2015) define a los hablantes de lengua de herencia como: "[...] individuos que han sido expuestos a una lengua de inmigrante o minoría desde la infancia, quienes además son muy competentes en la lengua mayoritaria que se habla en la comunidad lingüística más extendida" (p. 168).

Además, también considera, en conjunto con los autores anteriormente mencionados, algunas características comunes a los hablantes de herencia propuestos por Zyzik (2016):

\section{Figura 1}

\section{Características comunes a los hablantes de herencia}

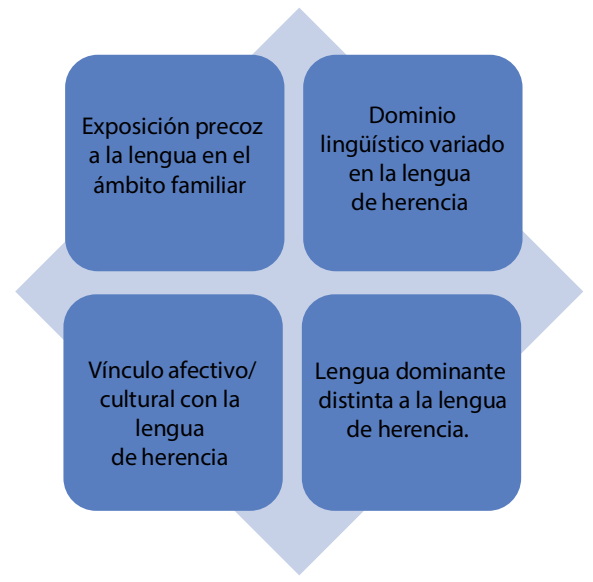

Fuente: Adaptado de Zyzik (2016).

Con respecto a la cultura de herencia, Fishman y Peyton (2001) ratifican la relación de interdependencia entre la lengua y cultura, proponiendo que, en realidad, los hablantes de herencia son sujetos aprendientes de una 
lengua relevante para su familia y por ende, a una cultura que se relacionará con la construcción de su identidad.

Tan relevante cuando la transmisión de la lengua de herencia, es conocer las tensiones y relaciones que emergen de estos individuos: su percepción de la realidad, el contacto con la cultura dominante y su cultura, como percibe el lenguaje estandarizado y el lenguaje de herencia, y cuáles son sus actitudes frente a esta lengua y cultura. Nesteruk (2010) asevera que mientras a unos la lengua y cultura son motivo de orgullo, para otros puede ser algo vergonzoso. Por lo tanto, la subjetividad que abarca este tema sitúa este estudio en un paradigma sociolingüístico, ya que como afirma He (2010) "la propia noción de lengua de herencia es sociocultural, dado que es definida en términos del grupo de personas que la hablan" (p. 66).

Además de la lengua, los comportamientos culturales también se presentan de manera diferenciada por los niños que viven en una familia y contexto multicultural. Cruz-Ferreira (2006) pacta con esta idea opinando que "la práctica del comportamiento diferencial en los ambientes culturales y la coherencia de estos en cada uno de los niños, refuerza el sentido de comunidad que es el sello de una herencia cultural" (p. 291).

En el caso de los hijos de inmigrantes, los referentes simbólicos relacionados a la identidad del país de origen se constituyen de manera distinta a los de sus ascendientes. Los hijos de inmigrantes que emigraron en edad temprana o nacieron en el país de residencia poseen una lengua y cultura de origen en virtud de sus familiares, empero, crecen en una sociedad distinta. Eso significa que el mantenimiento de los referentes de origen es realizado por los familiares y no por el entorno, como resalta Juliano (1994), "la experiencia común con sus connacionales se limita a un discurso compartido y aprendido" (p. 95).

Así, en esta situación habrá una carencia linguiística y cultural de las experiencias vitales. De esta manera, la construcción de una identidad colectiva relacionado al país de origen de los ascendientes no es un proceso natural. Mientras que el sujeto forma su identidad a partir de la interacción con la sociedad y, los hijos de inmigrantes crecen dentro de una sociedad distinta a la de sus familiares, su identidad será, por defecto, híbrida y compleja. Por lo tanto, aunque los hijos de inmigrantes crezcan estableciendo redes sociales de sus ascendientes, Maalouf (1999) manifiesta que "todos estamos infinitamente más cerca de nuestros contemporáneos que de nuestros antepasados" (p. 123). Eso significa que para que el proceso de construcción de la 
identidad cultural colectiva suceda con poca o ninguna vivencia en la sociedad de origen familiar, será necesario promover el máximo de contacto con el sistema de representaciones relativos a la lengua y cultura de sus progenitores y consideramos que ese sistema de representaciones es transmitido en primer lugar, por medio del lenguaje.

Flores y Melo-Pfeifer (2014) ratifican que el concepto de lengua de herencia (a partir de este momento, LH) todavía es un campo reciente de investigación, de compleja definición, sobre todo si consideramos la diversidad de conceptos para asignar la relación de los sujetos con la lengua, acercándose algunas veces a lo que por convención se nombra lengua materna (LM) o lengua extranjera (LE). Sobre la transmisión de la lengua y cultura de herencia, Carreira (2016) defiende que la lengua y cultura de herencia pueden ser aprendidas en tres contextos: clases de lengua de herencia, clases mixtas con hablantes de lengua extranjera y algunas opciones personalizadas, tales como estudios independientes y tutorías particulares. Asimismo, el primer y principal contacto será dado por el medio familiar.

Uno de los factores que influye en el aprendizaje de la lengua de herencia propuesto por Montrul (2015) es la actitud lingüística y la motivación por parte de los hablantes de herencia. Para Moreno Fernández (2005), "la actitud lingüística es una manifestación de la actitud social de los individuos, distinguida por centrarse y referirse específicamente tanto a la lengua como al uso que de ella se hace en sociedad" (p.177). La opción lingüística de un hablante por sus discursos está vinculada a un perfilamiento cognitivo y afectivo que representa sus percepciones subjetivas acerca de un contexto lingüístico y cultural. Además, Pearson (2007) destaca que la motivación para el aprendizaje y las actitudes frente a esta lengua y cultura están condicionadas a las actitudes de la familia, amigos y sociedad en general frente a la lengua y cultura minoritaria.

En el caso de los hijos de inmigrantes nacidos en el país de residencia, es decir, que no son inmigrantes, sino que tienen ascendencia extranjera, las actitudes pueden tener un componente afectivo y cognitivo, que pueden actuar de forma simbiótica o conflictiva (Trafimow \& Sheeran, 2005). En otras palabras, es posible que un hablante de herencia prefiera utilizar una variación de la LH, o incluso otra lengua con personas de su misma origen, en función del prestigio que tiene el idioma en su entorno (actitud cognitiva), pero que también prefiera utilizar la variedad que se habla en casa con personas de su familia o amigos íntimos, porque la considera más cercana 
y más cómoda (actitud afectiva). Estas elecciones pueden ser conscientes y pacíficas o motivo de stress y desconcierto por los hablantes de más de un origen. Estas actitudes no son permanentes y pueden variar de acuerdo con el contexto e interlocutor. Sin embargo, puesto que esta investigación se halla enmarcada en la sociolingüística y en la didáctica de la lengua, consideramos fundamental conocer las variables que circundan y afectan directa o indirectamente la enseñanza y el aprendizaje de la lengua y cultura de herencia. Respetar las opciones lingüísticas, considerando los conflictos relativos a las actitudes lingüísticas en un entorno de lenguas en contacto, es un requisito indispensable de un planteamiento didáctico para la enseñanza de una lengua y cultura de herencia. Saber evaluar el tipo de actitud y el nivel de motivación de los alumnos conlleva a que se pueda ofrecer situaciones de aprendizaje concernientes con las necesidades de los sujetos aprendientes.

Otro aspecto que influye en las actitudes lingüísticas es el prestigio social de la lengua en el país de residencia. Poersch (1995) en una investigación sobre los niños que viven en la frontera lingüística entre Brasil y Uruguay y no alcanzan la competencia comunicativa en los dos idiomas, defiende que esto refuerza la inseguridad y consecuentemente actitudes negativas ante una lengua u otra. Países con políticas linguiísticas más flexibles, que resaltan la importancia de la lengua y cultura local sin someter sus residentes a la aculturación, es decir, a la asimilación de la cultura local, colaborando con entidades internacionales y favoreciendo un diálogo intercultural, es un entorno que favorece las actitudes positivas frente al aprendizaje de la lengua y cultura de herencia.

Por fin, el último aspecto que incide en las actitudes lingüísticas y en la motivación de los hablantes de herencia es la motivación y la actitud lingüística de la familia ante la transmisión de la lengua y cultura de herencia a sus hijos. En la década de 70 y 80, Fishman (1980) resaltó la carencia de investigaciones acerca de los intereses y la motivación de los familiares, especialmente con el colectivo descendiente de inmigrantes. Según De Houwer (1999), el hecho de que los familiares crean en su rol de transmisión, puede influir en el desarrollo lingüístico de sus hijos y tiene un impacto en el mismo, simplemente porque esta creencia les hace actuar de una manera u otra.

De acuerdo con Spolsky (2009), las políticas lingüísticas familiares reúnen las creencias e ideologías sobre el lenguaje, las prácticas linguiísticas y los esfuerzos para establecer o modificar estas prácticas por medio de intervenciones en el ámbito familiar. McCarty (2011) testifica que ni siempre 
las políticas lingüísticas familiares son explicitas, pero que, sin embargo, se desprenden de las prácticas e ideologías presentes en el ámbito familiar.

Con respecto a las prácticas de la lengua de herencia, Döpke (1988, 1992) resalta como función prerrogativa de la familia insistir en el uso de la lengua minoritaria y utilizar algunas técnicas de enseñanza, adquiridas bajo consejo profesional, para ser aplicadas con los niños en el ámbito familiar. $\mathrm{El}$ autor destaca la estrategia one parent, one language (un familiar, una lengua), para explicar la organización lingüística familiar en la que los familiares establecen idiomas de comunicación distintos con sus hijos.

\section{La inmigración brasileña en España y el portugués como lengua de herencia (POLH, PHL) en Cataluña}

Los brasileños empiezan oficialmente su jornada migratoria en las últimas décadas del siglo XX. Hasta la década de 1960, Brasil era un país de acogida a un gran contingente de europeos y asiáticos. No obstante, a partir de la década de ochenta, comienza a sufrir un cambio de perspectiva. Esta década es conocida por economistas en Latinoamérica como la década perdida. Solé, Cavalcanti y Parella (2011) apuntan como principales causas las sucesivas crisis económicas, las omnipresentes migraciones afectivas y la pérdida de poder adquisitivo de las clases medias como factor contundente de la emigración brasileña. Un agravamiento de la desigualdad social, de la pobreza, una inflación desenfrenada y el aumento del desempleo, hicieron con que los brasileños empezaran a mirar al extranjero, primeramente a los Estados Unidos, como una alternativa para mantener los recursos amenazados por las frecuentes crisis económicas en Brasil y luego al continente asiático y europeo. A partir de esta situación, Brasil empieza a ser exportador de mano de obra, en una corriente que ha provocado la emigración de más de tres millones de brasileños.

Póvoa Neto (2006), destaca como principales zonas demográficas de residencia, Estados Unidos, Japón, Portugal, Reino Unido y España. Estados Unidos todavía sigue siendo el país que recibe el mayor número de brasileños. La inmigración hacia Japón también es considerable, aunque en este caso hay una situación muy específica, ya que son los descendientes de japoneses los que emigran, bajo condiciones legales especiales para este grupo. La emigración hacia el continente europeo ocurre por otras variables. Una 
de las principales ventajas de emigrar hacia el continente europeo, es que muchos brasileños poseen doble nacionalidad, en virtud de los familiares que emigraron hacia Brasil desde el del siglo XIX.

De acuerdo con el Informe Brasileiros no Mundo ${ }^{1}$ (2016), España es el tercer principal país de acogida a los brasileños. Según el Instituto Nacional de Estadística de España ${ }^{2}$ (2016), los brasileños están distribuidos por algunas regiones específicas. Cataluña concentra el mayor contingente, con $22 \%$ de la población. Madrid es la segunda, con 17\%, seguida por Andalucía $(10 \%)$ y Galicia $(9 \%)$.

El hecho de que muchas parejas son mixtas, es decir, tienen distintos orígenes, quita el protagonismo del portugués inclusive en el ámbito familiar ya que los familiares tienen que negociar los usos lingüísticos dentro de casa. Todo este escenario conforma un reto laborioso: ¿Cómo hacer que los niños conozcan la cultura brasileña y aprendan la lengua portuguesa en un contexto considerado exolingüe? Esta modalidad lingüística es llamada portugués como lengua de herencia (también conocido como POLH o PLH) y es transmitida mayoritariamente en el ámbito familia, pero también en asociaciones que promueven el POLH/PLH en diversos países del mundo. Estas iniciativas suelen ofrecer clases de portugués con una didáctica específica, además de promover fiestas y eventos consonantes con el calendario brasileño.

\section{Método}

El contexto elegido para el estudio es la Associação de Pais de Brasileirinhos na Catalunha (APBC). La APBC es una asociación sin ánimo de lucro, fundada en el año 2010 por un grupo de familias brasileñas residentes en Barcelona, con el objetivo de ofrecer clases de portugués y actividades relacionadas con la cultura brasileña a los descendentes de brasileños entre dos y doce años que residen en esta región. Por ser una Asociación, las clases están adscritas a la modalidad no formal.

Este estudio es parte de una investigación doctoral, con énfasis en la definición de directrices didácticas para la transmisión de una lengua de herencia en un contexto no formal. La investigación presenta una mirada cua-

1 Recuperado de: https://goo.gl/TM56eh

2 Recuperado de: https://goo.gl/XP1FT7 
litativa a partir del método de estudio de caso único (Stake, 2010), con sus raíces en la corriente fenomenológica, buscando participar de una construcción social, interpretando y dando sentido a un fenómeno, en consonancia con los significados que los sujetos participantes del estudio le consienten.

De acuerdo con Van Manen (2003), este tipo de estudio busca descubrir y atribuir sentido y valor pedagógico a los fenómenos educativos. Esta investigación educativa busca comprender una realidad desde una mirada holística e interpretativa, en un proceso de reflexión y elaboración de conocimientos que nace del contexto de investigación. Desde la mirada de la fenomenología hermenéutica, "la interpretación empieza siempre con conceptos previos del investigador que tendrán que ser sustituidos progresivamente por otros más adecuados" (Gadamer, 2001, p. 332).

El interés principal de este corte en la investigación es identificar las estrategias familiares para la transmisión de la lengua de herencia en un contexto multicultural como el de Cataluña, así como analizar la percepción que tienen sobre las actitudes lingüísticas que presentan sus hijos hacia el portugués como lengua de herencia. Analizando los objetivos de esta investigación, este estudio se sitúa en un paradigma cualitativo-interpretativo, en el que se propone elaborar constructos teóricos para los fenómenos observados (Sandín, 2003).

Para conformar el grupo de participantes, se consideraron como criterios, ser familiar (padre o madre) de un niño ${ }^{3}$ :

- Con ascendencia directa brasileña, proveniente del padre o de la madre, lo que les define como hablantes de herencia.

- Nacido o viviendo en Cataluña (España) desde una edad muy temprana.

- Que participara de las clases semanales de portugués como lengua de herencia y actividades culturales promovidas por la Associação de Pais de Brasileirinhos na Catalunha (APBC).

- Tuviera entre 5 (cinco) y 7 (siete) años, en fase de desarrollo de las competencia lectoescritora en el momento del estudio de campo.

3 Se utiliza la forma masculina para referirse a niños o niñas. Se adoptó este estilo únicamente para evitar sobrecarga en el texto. 
Finalmente, el grupo de participantes se compuso con once personas: seis padres brasileños con pareja extranjera y cinco madres brasileñas con pareja extranjera.

El instrumento elegido fue la entrevista semi-estructurada. La pauta de entrevista fue construida con vistas a comprender la visión de los familiares sobre algunas dimensiones relacionadas a:

- Las concepciones que poseen sobre la transmisión de la lengua y cultura brasileña y cómo se desarrolló este proceso en el ámbito familiar.

- Las políticas lingüísticas familiares, relacionada con el uso de la lengua en casa y la actitud de los familiares frente al POLH.

- La relación con la Associação de Pais de Brasileirinhos na Catalunha y sus expectativas con respecto a su trabajo pedagógico.

- Las proyecciones que tienen acerca de la enseñanza del POLH para sus hijos.

\section{Tabla 1}

Guion preguntas para entrevista semi-estructurada con familiar

\begin{tabular}{|c|c|}
\hline Dimensiones & Preguntas \\
\hline \multirow{4}{*}{ Concepciones } & ¿Desde cuándo tiene preocupación por que su hijo hable portugués? \\
\hline & ¿Esta preocupación fue apoyada por su pareja no brasileña? \\
\hline & $\begin{array}{l}\text { ¿Cuáles son las mayores dificultades en la transmisión de la lengua } \\
\text { y cultura brasileña? }\end{array}$ \\
\hline & $\begin{array}{l}\text { ¿Qué contacto tiene su hijo con la culturas o costumbres tanto de } \\
\text { Brasil como del país de su pareja? }\end{array}$ \\
\hline \multirow{4}{*}{$\begin{array}{l}\text { Políticas lingüísticas } \\
\text { familiares }\end{array}$} & ¿Cuáles las lenguas habladas en el ámbito familiar? \\
\hline & ¿Cómo se dio el desarrollo del lenguaje de su hijo? \\
\hline & ¿Existe una preferencia para las lenguas que se hablan en casa? \\
\hline & $\begin{array}{l}\text { ¿De qué manera promueve el portugués y la cultura de Brasil con } \\
\text { su(s) hijo(s)? }\end{array}$ \\
\hline \multirow{3}{*}{$\begin{array}{l}\text { La Asociación de Familiares } \\
\text { de Brasileirinhos en } \\
\text { Cataluña (APBC) }\end{array}$} & ¿Qué espera del trabajo de la APBC? \\
\hline & $\begin{array}{l}\text { ¿Desde que su hijo frecuenta las clases, ha percibido alguna } \\
\text { diferencia con respecto al uso de la lengua portuguesa? }\end{array}$ \\
\hline & $\begin{array}{l}\text { ¿Cómo cree que el trabajo pedagógico de la APBC podría ser } \\
\text { mejorado? }\end{array}$ \\
\hline
\end{tabular}


Las entrevistas se realizaron personalmente en la APBC, grabadas en audio y transcriptas en documento editor de texto. Tras finalizar la descripción y siguiendo los criterios de rigor éticos dentro de la investigación cualitativa, las transcripciones han sido entregadas a los entrevistados para su análisis y posibles rectificaciones. Al final de este proceso, todos los entrevistados estuvieran de acuerdo con la transcripción de su entrevista y así, fue posible proceder al análisis de datos.

\section{Análisis y resultados}

El análisis de datos se realizó con el soporte del programa Atlas Ti, versión 7.0 a través del método de análisis del discurso (Bardin, 1991). El hecho de realizar las entrevistas personalmente, con grabación de audio y posterior transcripción, posibilitó el análisis a través de este método, en función de ser posible interrogar los sentidos explicitados de forma verbal y no verbal. En las entrevistas, algunos familiares consideraron necesario presentar fotos y videos de sus hijos para ilustrar su discurso.

Por ser un estudio de caso único de corte cualitativo, las categorías nacieron del primer análisis de datos, en un total proceso inductivo (Stake, 2010).

Tras un primer análisis de las entrevistas, se definieron tres categorías:

- Concepciones familiares sobre la transmisión del POLH

- Políticas lingüísticas familiares relacionadas con el POLH

- Percepciones familiares sobre el trabajo de la APBC

Para presentar los datos, se utilizó el sistema de códigos dentro del programa Atlas TI.

ENT, 1:12 en el que E significa entrevista, 1 es el número del documento primario y 12 el número de la cita. Aunque las entrevistas se hicieron originalmente en portugués, se consideró pertinente traducirlas al castellano para facilitar su comprensión.

\section{Concepciones familiares sobre la transmisión del POLH}

Por lo que respecta a la transmisión y la manutención de una lengua y cultura de herencia, la familia es la que detiene el papel protagonista en di- 
cha labor, puesto que la conexión existente entre lengua, cultura e individuo es fruto del origen y del vínculo familiar (Spolsky, 2012). Por esta razón, toda y cualquier enseñanza de lengua de herencia nace del deseo y expectativa de la familia de origen extranjera que sus descendientes sean capaces de comprender y comunicarse en su idioma materno.

La enseñanza de la lengua de herencia solo cobra sentido cuando la familia está completamente involucrada en este proceso (Ada \& Baker, 2001).

Naturalmente, el hecho de que las familias pertenezcan a una Asociación y participen de sus actividades todos los sábados por la mañana y que, además, se hayan ofrecido voluntariamente para colaborar con una investigación relacionada con esta temática, revelan el interés por que sus hijos puedan aprender el portugués y la cultura brasileña.

\begin{tabular}{|l|l|}
\hline ENT 11:1 & $\begin{array}{l}\text { Cuando supimos que íbamos a tener un hijo, yo pensé, yo soy brasileño, ya sé } \\
\text { cómo será, independiente de lengua de herencia y estas cosas, lo primero que } \\
\text { me vino a la mente fue... ya en el primer contacto, cuando todavía estaban en el } \\
\text { vientre.. fue en portugués, naturalmente. }\end{array}$ \\
\hline ENT 12:1 & $\begin{array}{l}\text { No hay un momento concreto, simplemente ocurre naturalmente, con ellas } \\
\text { yo hablo mi lengua, no hablo otra lengua y, obviamente para que hablen mi } \\
\text { lengua, ellas deben aprender mi idioma, así que en casa, siempre les hablé en } \\
\text { portugués. }\end{array}$ \\
\hline ENT 9:2 & $\begin{array}{l}\text { Fue un esfuerzo, no exactamente un esfuerzo, pero fue un trabajo así de } \\
\text { consciencia, de empezar a utilizar el portugués con él, porque no era algo } \\
\text { normal en mi contexto, en mi día a día, de relaciones sociales, no era mi lengua } \\
\text { más habitual, en aquel momento no era natural hablar portugués. }\end{array}$ \\
\hline
\end{tabular}

\section{Políticas lingüísticas familiares relacionadas con el POLH}

A pesar de que los familiares expresan distintas posiciones acerca del momento y de la manera de transmitir su lengua y cultura a los hijos, para algunos como algo natural, para otros como un esfuerzo importante de su parte, todos, en consonancia con los estudios de Oh y Au (2005), han demostrado ser conscientes de que el éxito de la transmisión de la lengua de herencia está vinculado con su motivación en hacerlo primeramente en el ámbito familiar. 


\begin{tabular}{|l|l|}
\hline ENT, 11:13 & $\begin{array}{l}\text { Si estamos los tres en la misma mesa, cenando, sí, el portugués impera, } \\
\text { porque de alguna manera yo siempre impongo el portugués entre nosotros. }\end{array}$ \\
\hline ENT, 12:7 & $\begin{array}{l}\text { Claro, yo siempre hablo portugués, mi esposa siempre habla castellano y } \\
\text { ellas hablan el idioma de acuerdo con la persona con quien quieren hablar, } \\
\text { así que conmigo en portugués y el catalán con personas en la calle. }\end{array}$ \\
\hline
\end{tabular}

En el caso de una sola familia, el portugués no es hablado en casa, dado que el familiar brasileño relata haber perdido mucho del idioma portugués y que actualmente habla portuñol, una interlengua entre el portugués y el castellano:

\begin{tabular}{|l|l|}
\hline ENT 10:3 & $\begin{array}{l}\text { Es que automáticamente yo empiezo a hablar y ya viene un portugués } \\
\text { mezclado con el español y cuando me doy cuenta ya estoy hablando } \\
\text { castellano, así que me es difícil mantener el portugués. }\end{array}$ \\
\hline
\end{tabular}

En este caso, se denota un conflicto relacionado con la creencia de Impacto citada por De Houwer (1999). Para esta situación, sería necesario ofrecer orientación respecto a propuestas alternativas de usos del portugués en algunos momentos clave para facilitar la organización mental del niño.

Respecto a las opciones lingüísticas familiares, en el caso de los participantes se denotó que en la totalidad de las familias, padre y madre hablan o al menos entienden el idioma uno del otro, lo que favorece la comunicación en más de un idioma dentro de casa:

\begin{tabular}{|l|l|}
\hline \multirow{5}{*}{ ENT, 9:8 } & $\begin{array}{l}\text { Yo creo que es un valor de toda la familia, porque yo hablo castellano muy bien, } \\
\text { ahora también hablo catalán, mi marido quiso aprender portugués y aprendió tan } \\
\text { bien que se formó traductor, también vivió en Brasil tres años, tiene amigos allá, } \\
\text { así que el portugués para él también tiene un significado muy diferente del que } \\
\text { tenía cuando nos conocimos. }\end{array}$ \\
\hline
\end{tabular}

Por esta razón, los entrevistados consideran positivo el apoyo de la pareja no brasileña en la transmisión de la lengua de herencia, afirmando que el hecho de que el familiar no brasileño al menos comprenda el portugués, posibilita la creación de un contexto lingüístico en el que se favorece la comunicación en más de un idioma dentro de casa, creando un contexto de diversidad lingüística que proporciona también el desarrollo de la lengua de herencia. 
Gran parte de las familias relata haber sentido apoyo de su pareja no brasileña en la decisión de optar por la lengua portuguesa para establecer la comunicación con sus hijos:

\begin{tabular}{|l|l|}
\hline ENT 11:5 & $\begin{array}{l}\text { Su actitud siempre fue y aun es espectacular en este sentido. Ella también } \\
\text { quiere que las niñas aprendan, ya no es solo una cuestión mía, ella como madre } \\
\text { también tiene orgullo en saber que sus hijas comparten otra cultura y hablan } \\
\text { otro idioma. }\end{array}$ \\
\hline
\end{tabular}

Respecto a las preferencias y usos lingüísticos de los niños en diferentes contextos, mientras que algunas familias consideran el catalán como la lengua prioritaria de sus hijos y se lo atribuyen al hecho de que la escuela pública priorice este idioma, hay familiares que han relatado que sus hijos demuestran preferencia por la lengua castellana. En este caso, se denota que son los niños que tienen como padre o madre españoles, no catalanes, de forma que en el entorno familiar se habla el portugués y el castellano, mientras que el catalán se hablará especialmente en el entorno escolar.

\begin{tabular}{|l|l|}
\hline \multirow{5}{*}{ ENT, 12:5 } & $\begin{array}{l}\text { Ellas naturalmente hablan castellano, es su lengua materna...portugués...ellas } \\
\text { son trilingües, en catalán, español y portugués, pero el portugués es una lengua } \\
\text { más difícil. Como saben que conmigo solo deben hablar portugués, muchas } \\
\text { veces las veo pidiendo más cosas a su madre, porque es más fácil hablar en } \\
\text { castellano.... así, no tienen que estar pensando en cómo hablar en portugués. }\end{array}$ \\
\hline
\end{tabular}

No obstante, en el caso de este alumno, esta relación entre dominio y preferencia se denota porque el familiar no suele hablar en portugués. La adquisición temprana no se llevó a cabo como en el caso de los niños de lengua materna, de manera que este alumno es bilingüie pasivo, es decir, comprende el idioma, pero no se expresa verbalmente en esta lengua. Asimismo, no se trata solamente de preferencia lingüística como menciona el familiar, sino que el alumno no tiene las herramientas básicas para expresarse oralmente en portugués.

Corroborando los estudios de Broeder y Mijares (2003), otros familiares revelan que las lenguas preferidas de sus hijos son diferentes al portugués y esto ocurre en función de la dificultad que representa el portugués en un contexto exolingüe. Uno de los familiares también declaró que su hijo prefiere no utilizar el portugués: 
De acuerdo con Ortiz Álvarez (2016), las actitudes lingüísticas se conforman por tres elementos clave: las creencias, la valoración y la conducta de los individuos. En el caso de los hablantes de herencia, hemos encontrado que la valoración y las creencias de los participantes son en general positivas e íntimamente vinculadas a las actitudes de sus familiares.

En líneas generales, los familiares destacan los viajes a Brasil, las visitas de amigos brasileños y la convivencia con la familia brasileña en general, tanto por medio de visitas como por videoconferencias, como los principales soportes en la construcción y mantenimiento de los lazos afectivos con Brasil.

En primer lugar, se confirma por medio de las entrevistas, que los niños participantes han estado en Brasil, al menos una vez. Todos los familiares entrevistados admitieron que ninguna estrategia de transmisión supera un viaje al Brasil y el contacto humano con los familiares.

Uno de los familiares relata que fue el primer viaje a Brasil que realmente provocó la tomada de consciencia de los hijos sobre la importancia de saber hablar portugués en un contexto en el que solo se habla este idioma:

\begin{tabular}{l|l} 
& También es cierto que ellas empezaron a utilizar el portugués, así en serio, después \\
ENT, 12:8 su primer viaje a Brasil...solo ahí comenzaron a hablar esta lengua, con tres \\
años. No sé si sería así si no hubiéramos estado allá.
\end{tabular}

De acuerdo con las familias, las visitas de los familiares brasileños son importantes para el incremento en la cantidad y calidad del uso de esta lengua, como se observa en la siguiente cita:

\begin{tabular}{|l|l|}
\hline \multirow{2}{*}{ ENT, 9:12 } & $\begin{array}{l}\text { Mi madre estuvo aquí en las vacaciones, desde la mitad de agosto hasta la mitad } \\
\text { de septiembre, hace un mes que ella se fue. Con mi madre aquí, en casa, ellos } \\
\text { utilizaron mucho más el portugués, y aunque ya se ha ido, su presencia sigue aquí } \\
\text { en estos usos en portugués. }\end{array}$ \\
\hline
\end{tabular}

\section{Percepciones familiares sobre el trabajo de la APBC}

Con respecto a las expectativas que tienen los familiares sobre el conocimiento que tienen sus hijos sobre la lengua portuguesa y la cultura brasi- 
leña, la totalidad de los padres menciona como objetivo principal, que sus hijos tengan la capacidad de comunicarse en portugués, especialmente de forma oral:

\begin{tabular}{|l|l|}
\hline ENT, 9:22 & $\begin{array}{l}\text { Yo veo que las familias tienen algunas expectativas, no todas, pero creo que gran } \\
\text { parte de las que tienen niños mayores, les gustaría mucho que los niños pudieran } \\
\text { aprender a leer, a escribir en portugués y hacerlo bien. }\end{array}$ \\
\hline
\end{tabular}

Otra de las expectativas es que sus hijos se sientan brasileños y que, además, conozcan elementos de la cultura brasileña en general:

\begin{tabular}{|l|l|}
\hline \multirow{5}{*}{ ENT, 12:17 } & $\begin{array}{l}\text { Yo espero que ellas sean capaces de ser brasileñas, es (...), sin...sin miedo, que sean } \\
\text { brasileñas completas, que entiendan el portugués, que lean en portugués, que sepan } \\
\text { hablar como un brasileño, que sepan ir a Brasil y volver sin sentirse extranjeras en } \\
\text { Brasil. A pesar de que siempre serán, porque no van a tener el detalle, la cultura } \\
\text { en general. }\end{array}$ \\
\hline
\end{tabular}

Con respecto a las expectativas relacionadas con el trabajo de la Asociación de Padres de Brasileños en Cataluña (APBC), la totalidad de los familiares de los participantes relata que su propósito en llevar los hijos a las clases de portugués de la APBC es ofrecer otro espacio en el cual se hablara $\mathrm{y}$, especialmente, se valorizara la lengua y la cultura de Brasil.

\begin{tabular}{|l|l|}
\hline ENT, 12:14 & $\begin{array}{l}\text { Más gente, más gente utilizando la lengua...no tener un efecto isla...esta lengua } \\
\text { rara que habla papá... que sea una lengua normal. }\end{array}$ \\
\hline ENT, 13:22 & $\begin{array}{l}\text { Creo que realmente ella solamente empezó a hablar de verdad cuando comenzó } \\
\text { a frecuentar las clases de la Asociación. Yo percibí mucha diferencia. A ella le } \\
\text { gustaban las clases, tenía ganas de integrarse, así que aquella lengua que ella solo } \\
\text { conocía de escucharme, empezó literalmente a salir } * \text { risas. }\end{array}$ \\
\hline
\end{tabular}

\section{Discusión y conclusiones}

La mayoría de los familiares entrevistados son conscientes de su papel crucial en la transmisión de una lengua y cultura distinta a la mayoritaria. Sea de forma natural, por transmitir la lengua familiar, sea por que aprendan 
una lengua distinta y una cultura relacionada con su origen, los familiares consideran una riqueza y un derecho de los niños aprender la lengua y cultura de sus padres. En este estudio, en que las parejas eran en su totalidad mixtas, es decir, un brasileño y otro no brasileño, se concedió especial atención a la actitud positiva del familiar no brasileño como un soporte para la transmisión en el ámbito familiar.

Las principales dificultades detectadas por las familias se relacionan con la restricción de usos lingüísticos, y la actitud de los hablantes de herencia hacia la lengua de herencia. Por lo que respecta a la restricción de contextos, las familias valoran la Asociación (APBC) como un agente complementario a su trabajo en la transmisión de lengua y cultura. Sobre la actitud lingüística, las familias reconocen que los niños crecen, estudian y juegan en la lengua mayoritaria, razón por la cual demuestran mayor interés por esta lengua y no la lengua familiar.

Los entrevistados destacan los viajes a Brasil y las visitas de los familiares brasileños como elementos ratificadores del vínculo con la lengua y la cultura. Es a través del contacto humano que los niños toman consciencia de la importancia de hablar portugués. Además, ven la APBC como un soporte importante, puesto que es un espacio de interacción entre iguales, en el que sus hijos puedan jugar, conversar, aprender y convivir con otros niños en situación semejante. Para las familias, la APBC se convierte en un aliado en el papel de transmisión de la lengua y la cultura, en la construcción de la identidad y la valorización de la diversidad.

A pesar de los esfuerzos familiares, los padres consideran que enseñar una lengua y cultura fuera del ámbito escolar no es una labor fácil. Una vez entren en el sistema educativo local, los niños empiezan a cuestionar o incluso rechazar la lengua familiar (Montrul, 2015). El reto reside en transformar la diversidad lingüística y cultural como un motivo de orgullo. Lo que sí es esencial es analizar si el contexto para el desarrollo de la competencia comunicativa en esta lengua es favorable y si no, pensar en estrategias de sensibilización sobre las ventajas de dominar más de una lengua y cultura. En un ámbito micro, analizar el discurso de los niños sobre la lengua y cultura familiar también puede contribuir en diagnosticar las necesidades de aprendizaje y reevaluar las estrategias que se están empleando en esta transmisión. Lo que sí se refleja en los resultados es que solamente comunicarse en este idioma no es suficiente para la adquisición y desarrollo de la competencia comunicativa y/o el establecimiento de vínculos afectivos. Lo que 
más fortalece estos lazos es la interacción social y las vivencias realizadas por el sujeto. Para esto, la familia y toda la red de apoyo existente, deben ser conscientes y activas en su rol transmisor.

\section{Agradecimientos}

La autora agradece a la Associação de Pais de Brasileirinhos na Catalunha (APBC) y, especialmente, a los familiares participantes de esta investigación.

\section{Bibliografía}

Ada, A. F., \& Baker, C. (2001). Guía para padres y maestros de niños bilingües. Clevedon: Multilingual Matters.

Bardin, L. (1991). Análisis de contenido (Vol. 89). Ediciones Akal.

Benedict, R. (1997). O Crisântemo e a Espada. São Paulo: Perspectiva.

Broeder, P., \& Mijares, L. (2003). Plurilingüismo en Madrid: las lenguas de los alumnos de origen inmigrante en primaria. Madrid, España: Centro de Investigación y Documentación Educativa.

Cummins, J. (2005). A Proposal for action: Strategies for recognizing heritage language competence as a learning resource within the mainstream classroom. The Modern Language Journal, 89(4), 585-592.

Carreira, M. (2004). Seeking explanatory adequacy. A dual approach to understanding the term "heritage language learner". Heritage Language Journal, 2(1), 1-25. Recuperado de https://goo.gl/qYJsvL (3-05-2016).

Carreira, M. (2016). A General Framework and Supporting Strategies for Teaching Mixed Classes. En Pascual y Cabo, D. (Eds), Advances in Spanish as a Heritage Language (pp.159-176). Philadelphia: John Benjamins.

Cruz-Ferreira, M. (2006). Three is a crowd? Acquiring Portuguese in a trilingual environment. Clevedon, UK: Multilingual Matters.

De Houwer, A. (1999). Environmental Factors in Early Bilingual Development: The Role of Parental Beliefs and Attitudes. En Guus Extra y L. Verhoeven (Eds.), Bilingualism and Migration (pp. 75-95). Berlin: Mouton de Gruyter.

Döpke, S. (1988). The role of parental teaching techniques in bilingual GermanEnglish families. International Journal of the Sociology of Language, $72,101-112$. 
Döpke, S. (1992). One parent one language: An interactional approach. Amsterdam: John Benjamins.

Fishman, J. (1980). Ethnocultural dimensions in the acquisition and retention of biliteracy. Journal of Basic Writing, 3(1), 48-61.

Fishman, J., \& Peyton, J. K. (2001). 300-Plus years of heritage language education. En Peyton, J, Ranard, D. McGinnis, S. (Eds.), Heritage languages in America: Preserving a national resource language in education: Theory and practice (pp. 87-97). Washington, DC: Center for Applied Linguistics.

Flores, C., \& Melo-Pfeifer, S. (2014). O conceito Língua de Herança na perspetiva da Linguística e da Didática de Línguas: considerações pluridisciplinares em torno do perfil linguístico das crianças lusodescendentes na Alemanha. Domínios de Lingu@gem,8(3),pp.16-45.

Gadamer, H. G. (2001). Verdad y método. Salamanca: Sígueme.

Hall, S. (2003). Introducción: ¿quién necesita identidad? En S. Hall y P. Du Gay (Comps.), Cuestiones de identidad cultural (pp. 13-39). Buenos Aires: Amorrortu.

He, A. W. (2010). The heart of heritage: Sociocultural dimensions of heritage language learning. Annual Review of Applied Linguistics, 30, 66-82.

Juliano, D. (1994). Un lugar en el mundo: identidad, espacio e inmigración. Documentación Social: Revista de Estudios Sociales y Sociología Aplicada, 97, 91-100.

Maalouf, A. (1999). Identidades asesinas. Madrid: Alianza.

McCarty, T. L. (Ed.). (2011). Ethnography and language policy. New York: Routledge.

Montrul, S. (2015). The acquisition of heritage languages. Cambridge: Cambridge University Press.

Moreno Fernández, F. (2005). Principios de sociolingüística y sociología del lenguaje. Barcelona: Ariel.

Nesteruk, O. (2010). Heritage language maintenance and loss among the children of Eastern European immigrants in the USA. Journal of Multilingual and Multicultural Development, 31(3), 271-286.

Oh, J. S., \& Au, T. K. F. (2005). Learning Spanish as a heritage language: The role of sociocultural background variables. Language, Culture and Curriculum,18(3), 229-241.

Ortiz Alvarez, M.L. (2016). O Falante de herança: à procura de sua identidade. En M.L., Ortiz Alvarez y L. Gonçalves (Orgs.), O mundo do Português e o português no mundo afora: especificadades, implicações e ações (pp. 59-86). Campinas: Pontes.

Pearson, B. Z. (2007). Social factors in childhood bilingualism in the United States. Applied Psycholinguistics, 28 (03), 399-410. 
Poersch, J. (1995). Atitudes e aptidoes no ensino de línguas: é possível alfabetizar em lingua estrangeira? Letras de Hoje 30 (100), 193-205.

Póvoa Neto, H. (2006). A imagem da imprensa sobre a emigração brasileira. Estudos Avançados, 20(57), 25-39.

Sandín, M. P. (2003). Investigación cualitativa en educación: Fundamentos y tradiciones. Madrid: McGraw-Hill.

Solé, C., Cavalcanti, L., \& Parella, S. (2011). La inmigración brasileña en la estructura socioeconómica de España. Documentos del Observatorio Permanente de Inmigración 27, 9-211. Recuperado de https://goo.gl/h0tQgI (11-04-2016).

Spolsky, B. (2009). Language management. Cambrigde: Cambridge University Press.

Spolsky, B. (2012). Family language policy-the critical domain. Journal of Multilingual and Multicultural Development, 33(1), 3-11.

Stake, R. E. (2010). Qualitative research: Studying how things work. New York: Guilford Press.

Thomas, D. C., \& Peterson, M. F. (2015). Cross-cultural management: Essential concepts. Thousand Oaks: Sage.

Trafimow, D., \& Sheeran, P. (2005). A theory about the translation of cognition into affect and behaviour. En G. Haddock y G.R. Maio (Eds.), Contemporary perspectives on the Psychology of Attitudes (pp. 57-75). New York: Psychology Press.

Trujillo Saéz, F. (2006). Cultura, Comunicación y Lenguaje. Reflexiones para la enseñanza de la lengua en contextos multiculturales. Granada: Octaedro.

Valdés (2005). Bilingualism, heritage language learners, and SLA research: Opportunities lost or seized? The Modern Language Journal, 89(3), 410-426.

Van Deusen-Scholl, N. (2003). Toward a definition of heritage language: sociopolitical and pedagogical considerations. Journal of Language, Identity, and Education, 2(3), 211-230.

Van Manen, M. (2003). Writing in the dark: Phenomenological studies in interpretive inquiry. Walnut Creek: Left Coast Press.

Zyzik, E. (2016). Toward a Prototype Model of the Heritage Language Learner. En Fairclough y Beaudrie (Eds.), Innovative Strategies for Heritage Language Teaching: A Practical Guide for the Classroom (pp. 19-38). Washington, DC: Georgetown University Press.

Fecha de recepción: 2018/II/15; Fecha de aceptación: 2019/01/27;

Fecha de publicación: Fecha de publicación: 2019-03-0I 